\title{
A new method for processing clay-rich unconsolidated sediments for paleoecological investigations
}

\author{
Utsa Pollingher ${ }^{1}$, H. Ambühl2 \& H.R. Bürgi ${ }^{2}$ \\ ${ }^{1}$ Israel Oceanographic \& Limnological Research, Tel-Shikmona, P.O.B. 8030, Haifa 31080, \\ Israel, ${ }^{2}$ Swiss Federal Institute for Water Resources and Water Pollution Control (EAWAG), 8600 \\ Dübendorf, Switzerland
}

Received 1 May, 1990; in revised form 15 August, 1991; accepted 20 December, 1991

Key words: sediments, soft sediments, loose sediments, sampling, subsampling, cysts, dinoflagellates, freeze coring, Twin 80

\begin{abstract}
A method is described for processing flocculated clay-rich sediments which avoids acetolysis and heavy liquid separation. Twin 80 (Merck index 1983) is used for deflocculation. Microsieves separate the recovered organisms according to size. Taxonomic identification and quantitative evaluation of the organisms can be performed in counting chambers or on permanent slides. Algae, cysts and exospores of dinoflagellates, pollen grains and zooplankton remains can be recovered.
\end{abstract}

\section{Introduction}

The increased demand for more palaeoecological and palaeolimnological reconstructions and correlations requires more studies of lake sediments. Although lake sediments contain many preserved microfossil remains, in the past only pollen and diatoms were routinely recorded and studied. In recent years, special attention has been paid to cysts and scales of chrysophytes preserved in sediments (Smol, 1980, 1990; Battarbee, 1981; Haworth, 1983; Cronberg, 1985; Hartmann \& Steinberg, 1986; Kristiansen \& Andersen, 1986; Christie et al., 1988). Less attention has been paid to cysts of freshwater dinoflagellates.

The standard palynological method of sediment processing (Faegri \& Iversen, 1974) occa- sionally preserves some coenobial green algae: species of Pediastrum, Botryococcus, Scenedesmus, etc. This method, however, did not recover dinoflagellate cysts from the recent sediments of Lake Kinneret, where they are present due to a yearly water bloom of Peridinium gatunense (Pollingher, 1986).

More algal species were recorded when sediments were not treated chemically (Korde, 1966; Livingstone \& Jaworski, 1980). These authors worked with sediments rich in organic compounds (sapropel) and less, but still rich in, organic compounds ('depleted sapropel'). Kadota (1974), studying the microfossils from a core from Lake Biwa, heated the samples with concentrated HF followed by treatment with $10 \% \mathrm{HCl}$. Cronberg (1986) recommended a simple method of 
processing sediments, which she used with success in her study of subfossil algae (blue-green and green algae) from Lake Vaxjosjon (Sweden). Her method consisted of treatment with a solution of $10 \% \mathrm{NaOH}$ and staining with Fuchsin B-glycerin solution.

The above-mentioned methods however, proved to be unsuitable for flocculated and clayrich fossil and modern sediments from Lake Kinneret (Israel) and for loose laminated recent sediments from Lake Sempach and Lake Greifen (Switzerland). Mechanical ultrasonic bath sonication and chemical treatment (with $\mathrm{NaOH}$ or sodium pyrophosphate solution in a warm bath) did not dissociate the microfossils from the clayrich sediments. Therefore, the authors faced two important problems: 1) the recovery of undisturbed cores and the subsampling of soft and loose sediments, and 2) the devising of a suitable method of processing flocculated clay-rich sediments to recover all the algae preserved in recent and fossil sediments, with special emphasis on cysts of dinoflagellates and other algal propagules.

Twin 80 or Polysorbate 80 (Merck index 1983), a sorbitan monooleate polyoxyethylene; which is an amber colored viscous liquid that is very soluble in water, was used for deflocculating and dispersing the clay-rich sediments.

Existing piston corers or samplers (a review is given by Aaby \& Digerfeldt, 1986) are not generally appropriate for loose sediment. Although an adequate method that freezes the sediment in situ and handles it only when it is frozen has been described (Saarnisto et al., 1977; Saarnisto, 1986), it does not allow subsampling on the spot.

In order to obtain undisturbed cores from which subsamples can be taken on sites, the corer described by Ambuhl (1985) was used. A subsampling device was designed, and a new method of sediment processing was developed. This method does not use acetolysis, which seems to be harmful for some microfossils, nor heavy liquid separation. It is less time-consuming than standard palynological methods. Multisieve separation permits the recovery of preserved nanoplanktonic algae and other organisms (pollen, ciliates, cysts of protozoa and eggs of rotifers, etc.) and the elimination of clay without loss of other organisms. Quantitative recovery can be performed as well.

\section{Description of the procedure: sampling and pro- cessing of freshwater sediments}

\section{Field method}

The gravity corer designed and described by Ambuhl (1985) is $600 \mathrm{~mm}$ long and cuts a cylindrical undisturbed sediment core $110 \mathrm{~mm}$ in diameter and $300 \mathrm{~mm}$ long (Fig. IA).

The coring tube contains two slits through which a knife can be introduced. This knife is made of $1 \mathrm{~mm}$ mineral glass (thin window glass) with a sharp edge. To section the core, the tube is kept in a vertical position and the knife is carrefully introduced into the slits and guided by brass girders on both sides. After the knife has been completely inserted, the core's front half is removed (the material behind the glass is very soft and even partly liquid). The structure of the sediment is now clearly visible through the glass knife and ready for examination and documentation. The core is then fixed on its upper end by means of a piston that is anchored by a special clamp on the upper end of the coring tube. For subsampling, the whole device is now laid down horizontally. After removing the glass knife, the core is ready for subsampling (Fig. IB,E).

A device was developed for taking exactly positioned subsamples on site (Fig. 1C,D). It consists of a fixture designed to accommodate 4 adapted syringes with a volume of 1 or $2 \mathrm{~cm}^{3}$ each. The syringes, from which the bottom part (with the needle) is removed and the remaining tube sharpened, are positioned above the core by means of fixing the piston so that the lower end of the syringe cylinder is just on the core surface (produced by cutting with the previously mentioned glass knife). The cylinders are then pushed simultaneously into the sediment; thus they function as a small piston corer. The syringes are re-usable. Every subsample, consisting of $4 \mathrm{sy}$ ringes, contained $4-8 \mathrm{~cm}^{3}$ of sediments. These 

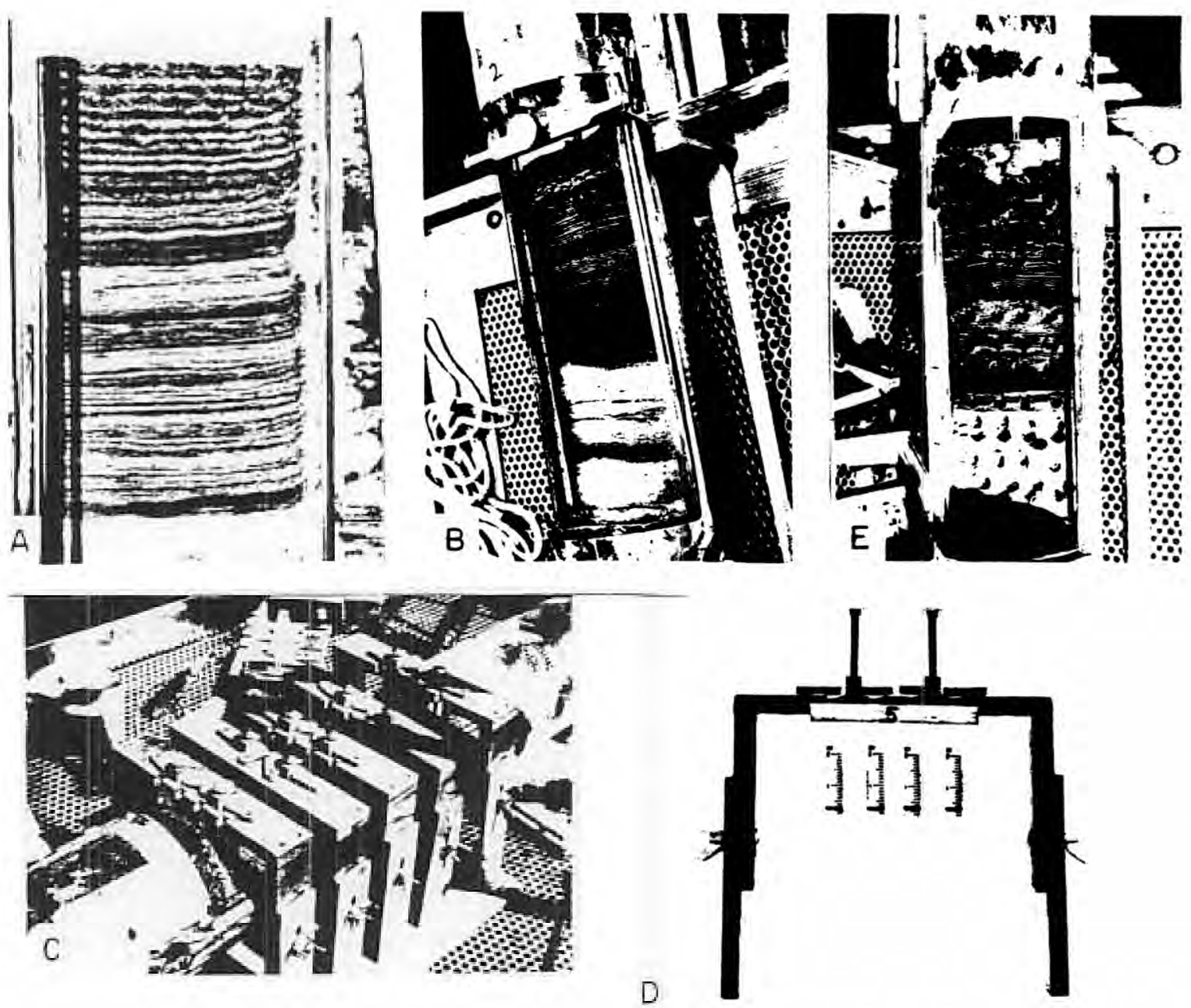

Fig. 1. The method of sampling. A - Sediment core from Lake Sempach. B - The core ready for subsampling. C, D - The de. vice for subsampling. $\mathrm{E}$ - The core after subsampling.

are preserved in plastic vials, and stored at low temperature $\left(2^{\circ} \mathrm{C}\right)$ in the dark.

For precise chronological research of laminated sediment cores with a stratigraphic accuracy of less than half a year, a freezing method was developed for subsampling sediments taken with the corer (Ambuhl, 1985), using a simple coring tube without any cutting slits, etc. With the corer in a vertical position, the top surface of the sediment core is pushed within a few centimeters of the upper end of the tube by introducing plastic discs $9.5 \mathrm{~cm}$ in diameter into the lower end. A thin-walled brass tube ( $20 \mathrm{~mm}$ diameter) is lowered from a support fixed at the top of the tube by a clamp into the fresh loose part of the core, down to the solid grey calcareous part $(20-30 \mathrm{~cm}$ below the sediment surface). The content of the brass tube is sucked out, and the tube is rinsed with distilled water, cleared with a vacuum device and kept filled with liquid nitrogen. After $10 \mathrm{~min}$ utes, a crust about $3 \mathrm{~cm}$ thick is frozen to the. brass tube. If the sediment core does not produce too much gas, the expulsion of which disturbs the sediment structure when the corer is brought to 
the surface (which is the case in some eutrophic sediments), this method provides an undisturbed sample of $250 \mathrm{~mm}$ length (Fig. 2). It can be washed and cut in a cold storage chamber, following Saarnisto (1986).

\section{Laboratory methods}

1. A measured volume of sediments is taken from each subsample and transferred to glass or pyrex centrifuge tubes (volume $50 \mathrm{ml}$ ).

2. The sample is mixed well with distilled water using a vortex mixer.

3. The sediments are separated from the liquid by centrifugation and decantation.

4. $\mathrm{HCl}$ acid $(35 \%)$ is added to remove carbonates. Sediments rich in carbonates have to be

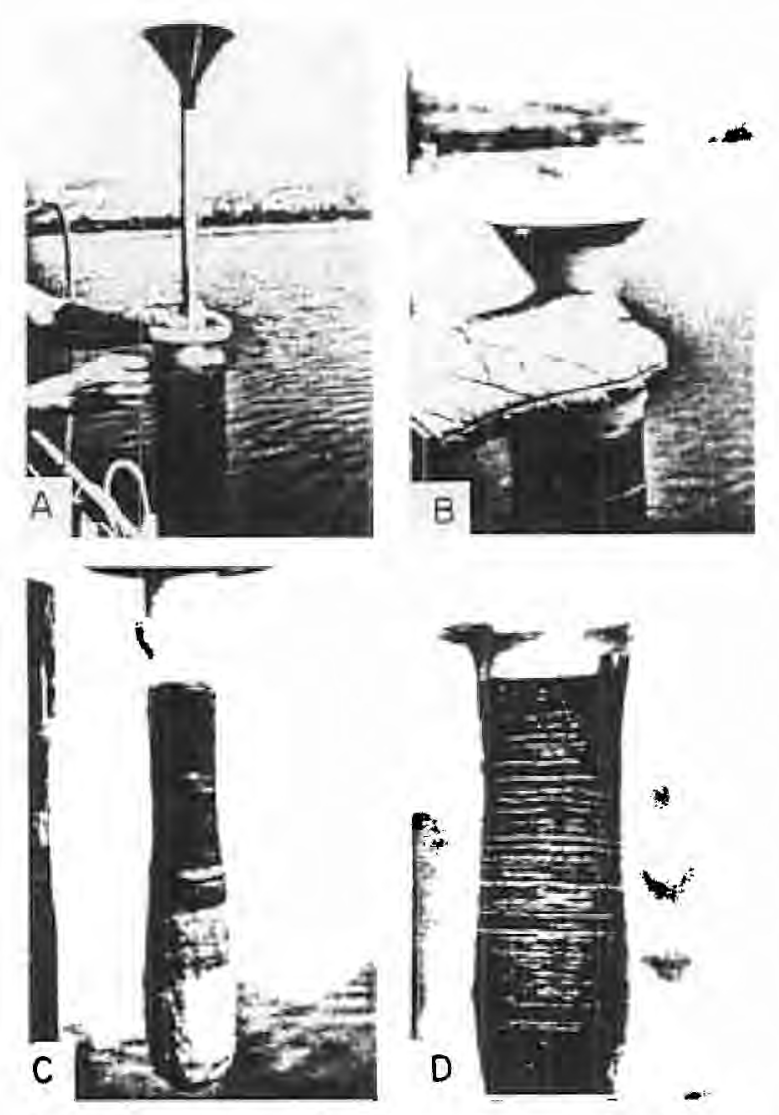

Fig. 2. Preparation of the frozen subsample. A - Subsam. pling. B - Freezing with $\mathrm{N}_{2}$. C. D - The frozen subsample. treated slowly, stirring and adding small quantities of $\mathrm{HCl}$ until the reaction stops.

5 . The samples are rinsed (2-3 times) with distilled water and transferred to plastic centrifuge tubes.

6. HF acid (ca. $50 \%$ ) is added to remove silicates. (For recovery of diatoms, this step is avoided).

7. After rinsing well, the residue is transferred back to glass tubes.

8. Deflocculation is performed by using a solution of $10 \% \mathrm{NaOH}$ or a solution of $5 \%$ sodium pyrophosphate $\left(\mathrm{Na}_{4} \mathrm{P}_{2} \mathrm{O}_{7}\right)$ for $10-20$ minutes in a boiling water bath.

9. The residue is rinsed and checked to see how well it is disaggregated.

10. Occasionally an ultrasonic bath may be tried for better disaggregation.

When the results are positive, the following steps 11 and 12 are avoided, and the processing continues with step 13. In the case of the clay-rich sediments, with which we worked, the above steps and the method of Bates et al. (1978) did not give satisfactory results. Therefore, steps 8,9 and 10 were avoided, and after step 7 the processing was continued with step 11.

11. Deflocculation and dispersion were achieved with a $5 \%$ aqueous solution of the oleate ester of sorbitol, Twin 80 for one hour.

12. In order to prevent reaggregation of the clay mineral particles, a saturated $\mathrm{NaCl}$ solution is recommended for the first rinse.

13. Following a multiple rinsing with distilled water, the material is preserved in a $4 \%$ formaldehyde solution.

14. After completion of the procedure, multiple microsieve separation is performed using meshes of $100,70,30$ and $10 \mu \mathrm{m}$. On the first two sieves, plant and large zooplankton remains are recovered; on the 30 and $10 \mu \mathrm{m}$ meshes, pollen grains, algae and cysts of dinoflagellates are separated. The authors use counting chambers $\left(2 \mathrm{~cm}^{3}\right.$ volume) and an inverted microscope for the taxonomic identification and quantitative evaluation of the organisms (Hasle; 1978). Phase contrast and high magnification can be used. Photographs are easily obtained. The residue can also be 

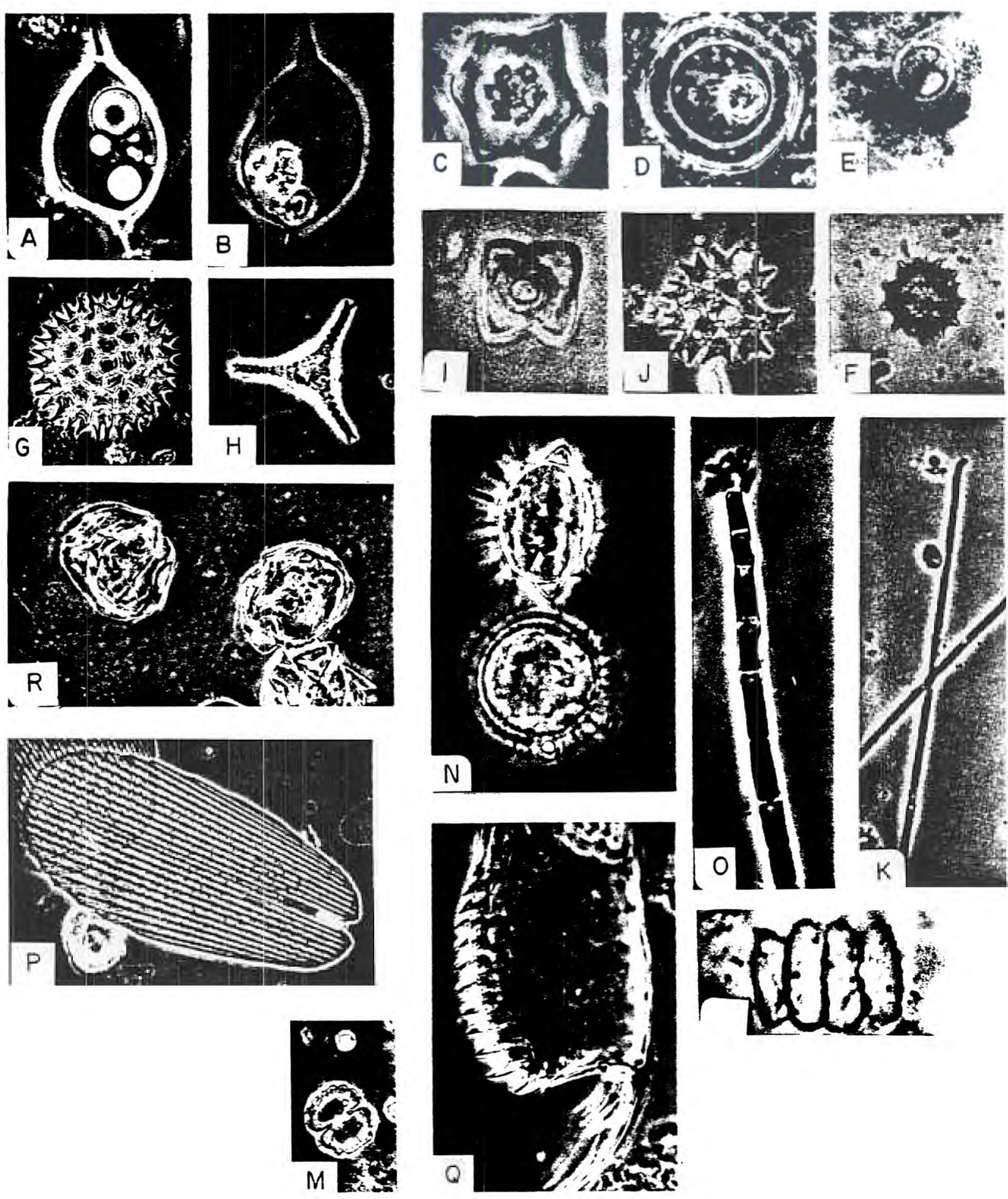

sedi 
stained, and permanent slides may be prepared.

The sieves are made in the laboratory using small cylindrical wide mouth plastic bottles equipped with plastic screw cap. The top of the cap and the bottom of the bottle are removed. The bottle mouth is covered with a piece of Nitex net (mesh sizes given above) and fastened (tightened) with the cap.

Using this method, the following were recovered: protozoa, pollen grains, fragments of zooplankton, eggs of zooplankton, coenobial, filamentous and nanoplanktonic algae, cysts of dinoflagellates, exospores of dinoflagellates, etc. This method does not destroy the chloroplasts (Fig. 3I,J). Examples of recovered organisms are given in Fig. 3.

The method allows one to obtain undisturbed samples and subsamples from loose sediments, while on site. The necessary equipment for sediment processing and study of the organisms is usually available in any standard limnological laboratory. The processing method is less timeconsuming than the standard palynological method (Faegri \& Iversen, 1974) and the method used for the recovery of sporopollenin cysts of marine dinoflagellates (Evitt, 1985). Acetolysis and heavy liquid separation are avoided. By avoiding acetolysis, which may have a destructive effect on some organisms, more of the organisms preserved in the sediments are recovered, including the chloroplasts of algae, exospores of dinoflagellates (from recent sediments), nanoplanktonic algae, etc.

\section{Acknowledgements}

Thanks are due to Dr. J.P. Smol and to two anonymous reviewers for suggesting helpful improvements to the earlier drafts. The research was performed during a sabbatical leave of the first author at the Department of Limnology at the EAWAG. The authors acknowledge the competent assistance of the departmental technical staff in the field work and in the laboratory. Thanks go to Mr. P. Schlup for help with the micrographs, and Ms. K. Diskin for typing the manuscript.

\section{References}

Aaby, B. \& G. Digerfeldt, 1986. Sampling techniques for lakes and bogs. pp. 187-201. In: Handbook of Holocene Palaeoecology and Palaeohydrology (B.E. Berglund ed.), John Wiley \& Sons Lid., New York.

Ambahl, H., 1985. Technik der Praparation und Darstellung von Sediment-Kernen mit grossem Querschnit. Schweiz. Z. Hydrol. 47: 249-256.

Bates, C. D., P. Coxon \& P. L. Gibbard, 1978. A new method for the preparation of clay-rich sediment sampies for palvnological investigation. New Phytol. 81: 459-463.

Battarbee, R. W., 1981. Diatom and Chrysophyceae microstratigraphy of annually laminated sediments of a small meromictic lake. Striae 14: 105-109.

Christie, C. E., J. P. Smol, P. Huttunen \& J. Merilainen, 1988. Chrysophyte scales recorded in lake sediments from eastem Finland. Hydrobiologia 161: 237-243.

Cronberg, G., 1985. Chrysophycean cysts and scales in sediments: a review. pp. 281-315. In: Chrysophytes - Aspects and Problems (J. Kristiansen \& R. A. Andersen, eds.), Cambridge University Press.

Cronberg, G., 1986. Blue-green algae, green algae and Chrysophyceae in sediments. pp. 507-526. In: Handbook of Holocene Palaeoecology and Palaeohydrology (B. E. Berglund ed.), John Wiley \& Sons Lid., New York.

Evitt, W. R., 1985. Sporopollenin Dinoflagellate Cysts: Their Morpholog; and Interpretation. Amer. Assoc. Strat. Palynol. Foundation, $333 \mathrm{pp}$.

Faegri, K. \& J. Iversen, 1974. Textbook of Pollen Analysis. Munksgaard, Copenhagen.

Harmann, H. \& C. Steinberg, 1986. Mallomonadacean (Chrysophyceae) scales: early biotic palaeoindicators of lake acidification. Hydrobiologia 143: 87-91.

Hasle. G. R., 1978. Using the invented microscope. pp. 8896. In: Phytoplankton Manual (A. Sournia, ed.), Monographs on Oceanographic Methodology, 6. UNESCO.

Haworth. E. Y., 1983. Diatom and chrysophyte relict assemblages in the sediments of Blelham Tam in the English Lake District. Hydrobiologia 103: 131-134.

Kadota, S., 1974. A quantitative study of microfossils in a 200 meter core sample from Lake Biwa. pp. 236-246. In: Palaeolimnology of Lake Biwa and the Japanese Pleistocene. 2. (S. Horie, ed.), Otsu, Japan.

Korde, N. W., 1966. Algenreste in Sedimenten zur Entwicklungsgeschichte der Seen und umliegenden Landschaften. Arch. Hydrobiol. Beih. Ergebn. Limnol. 3: 1-38.

Kristiansen, J. \& R. A. Andersen (eds.), 1986. Chrysophytes: Aspects and Problems. Cambridge University Press.

Livingstone, D. \& G. H. M. Jaworski, 1980. The viability of akinetes of blue-green algae recovered from the sediments of Rostherne Mere. Br. Phycol. J. 15: 357-364.

Pollingher, U., 1986. Non-siliceous algae in a five meter core from Lake Kinneret (Israel). Hydrobiologia 143: 213-216.

Saarnisto, M., 1986. Annually laminated lake sediments. pp. 343-370. In: Handbook of Holocene Palaeoecology 
and Palaeohydrology (B. E. Berglund, ed.), John Wiley \& Sons Lid., New York.

Saamisto, M., P. Huttunen \& K. Tolonen, 1977. Annual lamination of sediments in Lake Lovojavi, southern Finland, during the past 600 years. Ann. Bot. Fenn. 14: 3545.

Smol, J. P., 1980. Fossil synuracean (Chrysophyceae) scales in lake sediments: a new group of paleoindicators. Can. J. Bot. 58: 458-465.

Smol, J. P., 1990. Diatoms and chrysophytes - a useful combination in palaeolimnological studies: report of the workshop and a working bibliography. pp. 585-592. In: Proceedings of the Tenth International Diatom Symposium (H. Simola, ed.), Koeltz Scientific Books, Koenigstein. 